\title{
A multidisciplinary approach to diagnose naturally occurring bovine tuberculosis in Brazil ${ }^{1}$
}

\author{
Carla D. Marassi ${ }^{2 *}$, Luciana Medeiros ${ }^{2}$, Eduardo Figueiredo ${ }^{3}$, Leila S. Fonseca ${ }^{4}$, \\ Rafael Duarte ${ }^{4}$, Vania Paschoalin ${ }^{5}$, Walter M.R. Oelemann ${ }^{4}$ and Walter Lilenbaum ${ }^{2}$
}

\begin{abstract}
Marassi C.D., Medeiros L., Figueiredo E., Fonseca L.S., Duarte R., Paschoalin V., Oelemann W.M.R. \& Lilenbaum W. 2103. A multidisciplinary approach to diagnose naturally occurring bovine tuberculosis in Brazil. Pesquisa Veterinária Brasileira 33(1):1520. Laboratório de Bacteriologia Veterinária, Departamento de Microbiologia e Parasitologia, Universidade Federal Fluminense, Rua Prof. Hernani de Mello 101, Lab. 309, Niterói, RJ 24210-130, Brazil. E-mail: carladray@yahoo.com.br

A herd infected naturally with tuberculosis was investigated by different diagnostic methods. Ninety days after a screening test that identified 21 cows as skin test positive, a Comparative Intradermal Tuberculin Test (CITT) was performed in those 21 cows and in 29 other randomly selected skin test negative cows. Milk samples and nasal swabs were collected prior to the CITT for bacteriological culture and PCR, while blood samples were collected for IFN release and antibody responses to MPB70 and MPB83, at three time points post tuberculin injection. Animals positive by CITT were slaughtered and disease confirmation undertaken. Based on the Kappa test, IFN was comparable to the standard tests (culture, PCR and CITT) at all three sampling points. Results from both antibody ELISAs were similar but were not comparable to the standard tests. T-test analysis of the CITT, IFN and ELISAs demonstrated that their performances were not correlated. There is increasing recognition that individually, available diagnostic tests do not detect all infected cattle. Therefore, a comprehensive strategy for the diagnosis of bovine TB should include test results for the detection of both cellular and humoral immune responses where there may be animals at different stages of infection.
\end{abstract}

INDEX TERMS: Tuberculosis, serological, ELISA, MPB70, MPB83, IFN, cattle.

RESUMO. [Uma abordagem multidisciplinar para o diagnóstico de tuberculose bovina em um rebanho naturalmente infectado no Brasil.] Um rebanho bovino naturalmente infectado por tuberculose foi analisado através de diferentes métodos diagnósticos. Um teste intradérmico

\footnotetext{
${ }^{1}$ Received on July 16, 2012.

Accepted for publication on October 15, 2012.

${ }^{2}$ Laboratório de Bacteriologia Veterinária, Departamento de Microbiologia e Parasitologia, Universidade Federal Fluminense (UFF), Rua Prof. Hernani de Mello 101, Lab. 309, Niterói, RJ 24210-130, Brazil. *Corresponding author: carladray@yahoo.com.br

${ }^{3}$ Laboratório de Análises Microbiológicas, Departamento de Alimentos e Nutrição, Universidade Federal de Mato Grosso (UFMT), Rua da Universidade 2367, Boa Esperança, Cuiabá, MT 78060-900, Brazil.

${ }^{4}$ Laboratório de Diagnóstico Sorológico e Molecular, Instituto de Microbiologia Paulo Góes, Universidade Federal do Rio de Janeiro (UFRJ), Av. Carlos Chagas Filho 373, Bloco I, Lab. 043, Rio de Janeiro, RJ 21941-902, Brazil.

${ }^{5}$ Laboratório de Bioquímica e Biologia Molecular, Instituto de Química, UFRJ, Av. Athos da Silveira Ramos 149, Bloco A, 7o andar, Rio de Janeiro, RJ 21941-909.
}

simples (TIC) identificou 21 animais como positivos. Após 90 dias deste resultado, um teste intradérmico comparativo (TIC) foi aplicado nos 21 animais positivos ao TIS, além de outros 29 animais com resultados prévios negativos escolhidos aleatoriamente. De todos estes animais (50), foram coletadas amostras de leite e secreção nasal para isolamento e identificação de microrganismos por cultura e PCR; amostras de sangue de cada um dos animais foram coletadas para exames de ELISA: produção de Interferon-gama (IFN) e pesquisa de anticorpos frente aos antígenos MPB70 e MPB83. Tais amostras sanguíneas foram coletadas em três diferentes momentos: no dia da execução do TIC e nos dias dia 7 e dia 21 após a execução do TIC. Os animais que foram positivos a este teste foram abatidos; exames de identificação do agente, tais como cultivo e PCR foram realizados post-mortem para confirmação da doença. Baseado na análise Kappa, IFN apresentou resultados estatisticamente comparáveis aos resultados de isolamento e identificação bacteriana por cultura e PCR, além do TIC ao 
longo de todo o experimento. No entanto, TIC, ELISA e IFN não foram estatisticamente comparáveis. Tais resultados sugeriram que nenhum dos atuais métodos de diagnóstico para tuberculose possibilitou a identificação de todos os animais infectados. Por este motivo, uma estratégia mais abrangente deveria incluir métodos de diagnóstico que pudessem identificar a resposta imune celular e humoral, uma vez que animais de um mesmo rebanho poderiam se encontrar em diferentes estágios da infecção.

TERMOS DE INDEXAÇÃO: Tuberculose, sorologia, ELISA, MPB70, MPB83, IFN, bovinos.

\section{INTRODUCTION}

Tuberculosis (TB) in cattle caused by Mycobacterium bovis (M. bovis) remains an endemic infection in several countries, despite several efforts to control the disease. It causes considerable difficulties on cattle dairy farms and poses health risks to the population that consumes products of animal origin (Amanfu 2006, WHO 2009).

In the early stages of the infection, $M$. bovis elicits a cellular immune response that controls the spread of the microorganism throughout the host. As the infection progresses, a humoral response is more evident while cellular responses tend to diminish. During the early stages of infection there is a slight humoral response directed against a small number of $M$. bovis antigens although this response is less easily detectable. However, detection of this response could be very useful for accurate and sensitive diagnosis (Surujballi et al. 2002, Wiker 2009).

The tuberculosis lesions in cattle are most often found in organs rich in reticuloendothelial tissue, particularly lungs and associated lymph nodes, and liver (Neill et al. 1994). Other studies conducted on naturally and experimentally infected cattle demonstrated that lesions are most commonly observed in the lower respiratory tract; however the upper respiratory tract and associated tissues may also display disease in a significant number of cases (De la Rua Domenech et al. 2006, Rodgers et al. 2007). Although tubercles are not a pathognomonic lesion of cattle TB, the presence of clinical signs of the disease is directly associated to their distribution and quantity (Neill et al. 1994). In Brazil, experimental studies demonstrated similar findings as their previously described. Almeida et al. (2006) described lesions with an inflammatory infiltrate of predominant mononuclear cells in animals with positive intradermal test. In some of these animals, there were Langerhans' like giant cells, cell debris and also no delimited necrosis areas accompanied by vasculitis.

The gold standard for TB diagnosis is considered to be the isolation and identification of the microorganism (or its DNA) by bacteriological culture (or PCR) (Medeiros et al. 2010) using samples collected from suspect cases. Although both methods achieve high specificity, they can only be performed post-mortem and cultures may require incubation for four months. Milk samples can also be analyzed by bacteriological culture or PCR; however, microbial spread to the mammary glands is not necessarily reliable (Pollock et al. 2005). In addition, negative test results do not exclude the possibility of infection, especially in an area with low disease incidence and low bacteriological load, a complicating factor for accurate diagnosis (Lilenbaum 1999, Jolley et al. 2007).

Currently, the most widely employed diagnostic method is based on intradermal tests but they have limitations in both sensitivity and specificity (Monaghan et al. 1994). These tests are based on a measurable cellular immune response against $M$. bovis that is elicited during the first stages of the disease. They are performed as a single intradermal tuberculin test (SITT), based on the intradermal inoculation of $M$. bovis purified derivative protein (PPDB), or a comparative intradermal tuberculin test (CITT), utilizing PPDB and Mycobacterium avium PPD (PPDA). The CITT has a higher specificity by recognizing cross-reactive responses against environmental mycobacteria (Monaghan et al. 1994, Lilenbaum 1999, Jolley et al. 2007), and allows adjustment for final interpretation. The Gamma-Interferon assay (IFN) is also based on the cell-immune response and measures IFN released into whole-blood culture (Wood et al. 1990) in vitro, in response to specific antigen stimulation. This assay has been evaluated as a primary diagnostic method in many countries (Wood 2001), including Brazil, and has some important advantages (Lilenbaum, 1999). Since lymphocyte stimulation is done in vitro, and consequently does not alter the immune status of the animal, it is not necessary to wait 60-90 days to repeat the test when the initial test is inconclusive, a distinct limitation of the skin tests.

Serological assays are considered to be useful tools for the diagnosis of bovine tuberculosis although limited to those periods when antibodies are a feature of the disease. There is a switch in the nature of the immune response against $M$. bovis as the infection progresses. It is known that during the later stages of infection, there is a strong humoral response and assays based on the cell-immune response can be either negative or inconclusive. In addition, serological assays are relatively easy to perform and can be used to rapidly test a large number of samples (Surujbali et al. 2002, Medeiros et al. 2010). In addition, new antigens are being investigated with variable results in order to identify infected animals in the first stages of the disease and, in some countries, to differentiate infection from vaccination (Buddle et al. 1995, Lyaschenko et al. 2004). MPB70 and MPB83 have been used independently or in association with other important antigens, such as EAST-6 and CFP-10, for diagnosis purposes (Aagard et al. 2006). The MPB70 and MPB83 proteins are identified as early B-cell targets in $M$. bovis infection and could detect antibodies in experimentally infected cattle seven (MPB70) to 18 (MPB83) weeks before a positive tuberculin response could be measured (McNair et al. 2001, Lin et al. 2007). In addition, selection of highly specific antigens could help to eliminate cross-reactions between other species of mycobacteria, such as M. avium paratuberculosis and M. kansassii (El-Zaatari et al. 1995, Olsen et al. 2001, Water et al. 2006, Marassi et al. 2009a).

This project has been conducted for the last three years, and previous results were published, discussing separately 
the advantages and disadvantages of each diagnostic method. Therefore, it was published as short communications about multiplex PCR (Figueiredo et al. 2008), IFN (Marassi et al. 2009b) and ELISA (Lilenbaum et al. 2011). In this article, we propose a comprehensive discussion of the information obtained during the project, analysing the various diagnostic tools as a conjunct.

\section{MATERIALS AND METHODS}

Study design. This study was conducted on a dairy herd of 270 adult crossbred Holstein and Gir cows. Prior to the study, 21 adult cows had positive reactions to a SITT and were kept in quarantine for 90 days, waiting for confirmatory tests to be conducted. After 90 days, CITT was performed in these 21 cows plus 29 randomly selected cows that were negative to the first SITT test. Blood samples (for IFN testing and ELISAs) were collected from these 50 cows, at the time of the CITT (day 0), and seven ( $7 p . i$.) and 21 days (21p.i.) post injection of PPD (p.i.). At 30 days p.i., all CITT-reactive cattle were slaughtered and mediastinal, scapular and retropharyngeal lymph nodes, as well as lung samples, were collected and processed for bacterial culture and PCR. Milk and nasal swabs were collected from all 50 cows (on day 0 ) and prepared for bacteriological culture and PCR.

Intradermal tests. Intradermal tests (both SITT and CITT) for tuberculosis diagnosis were performed on 50 cows, in accordance with the regulations of the Brazilian Department of Agriculture. For SITT, 0.1mL of bovine PPD (PPDB - M. bovis strain AN5, $1 \mathrm{mg}$ protein/mL; Instituto Biologico, São Paulo, SP, Brazil) was inoculated in the cervical area of each cow. After $72 \mathrm{~h}$, the site of inoculation was measured with calipers, and the cow was considered reactive if a swelling $>4.0 \mathrm{~mm}$ occurred at the injection site. The CITT consisted of the same procedure, with an additional inoculation of $0.1 \mathrm{~mL}$ avium PPD (PPDA - M. avium strain D4, 0.5mg protein/mL; Instituto Biologico) in the cervical area, approximately $20 \mathrm{~cm}$ from the PPDB inoculation. Cattle were considered reactive if the difference between the thicknesses of both sites of inoculation were $>4.0 \mathrm{~mm}$. According to Brazilian laws, CITT was adopted as the standard test in the present study.

Interferon-gamma assay (IFN). Heparinized blood samples from the 50 cows were collected for IFN testing just prior to injection of PPD (day 0 ), as well as seven and 21 days later. The assay was performed according to the manufacturer's instructions (Bovigam, Prionics, Zürich, Switzerland), including the modifications recommended by Ryan et al. (2000) and with the same PPDs that had been used to perform the CITT.

MPB70/MPB83 - ELISAs. Use of the recombinant proteins MPB70 and MPB83 has been described previously (Lightbody et al. 2000, Marassi et al. 2009). Each antigen was used separately as a capture antigen in an ELISA and was diluted to a concentration of $1 \mu \mathrm{g} / \mathrm{mL}$ in $0.05 \mathrm{M}$ carbonate buffer, ( $\mathrm{pH} 9.8$ ) then used to coat a 96 well plate (Nunc maxisorb $₫$-USA) overnight at $8^{\circ} \mathrm{C}$. After six washes, the plate was blocked with $2 \%$ casein (Sigma-USA) in TBST (10mM Tris; 0.9\% NaCl; 0.1\% Tween20 - pH 7.5, all components made by Sigma, USA) solution for 60 minutes in room temperature with agitation. Plates were washed again and bovine sera, diluted to a concentration of 1 in 100 in TBST buffer with $1 \%$ casein added and incubated at $37^{\circ} \mathrm{C}$ under continuous agitation for 60 minutes. A secondary antibody, alkaline-phosphatase conjugated anti-bovine IgG was used $(1 / 5,000)$ and the reaction was revealed with p-NPP (para-Nitrophenyl phosphate) (1mg/ $\mathrm{mL}$ ) then stopped with $2 \mathrm{~N} \mathrm{NaOH}$ (Merck-USA) after 30 minutes in the dark. Optical density (OD) readings were measured using a spectrophotometer (model 680 BioRad, USA) at a wavelength of $405 \mathrm{~nm}$. Cut-off points based on OD readings were calculated using Receiver Operator Characteristic Curves (ROC) analysis (analyse-it@ - www.analyse-it.com) and concordance of tests measured using kappa index $(k)$. Sera were considered positive when OD results were greater than the cut-off value (0.100). Positive and negative sera controls were also tested by this assay. Negative sera presented ODs values of less than 0.06 .

Evidence of Mycobacterium bovis. All samples were processed for both bacteriology and PCR. To culture M. bovis, samples of tissues, milk and swabs were decontaminated according to standard methods (Lilenbaum 1999) and inoculated onto two slopes of solid, egg-based media Lowenstein-Jensen with $0.5 \%$ pyruvate, and two slopes of Stonebrink media, which were incubated at $37^{\circ} \mathrm{C}$ and observed once weekly for 12 weeks. For evidence of $M$. bovis-specific DNA, a multiplex PCR targeting the RvD1Rv2031c genomic sequence was employed (Figueiredo et al. 2008).

Statistics. Analysis of results was carried out using the Kappa test. Sensitivity and specificity were calculated for each test performed in this study [www.analyse-it.com].

\section{RESULTS}

\section{Definition of the infection status of cattle}

The total number of cattle infected with Mycobacterium bovis according to the standard tests (Culture or PCR or CITT), was 35 out of 50. From these cattle, 27 were positive on the basis of bacterial culture and PCR, while the remaining eight cows were considered infected based exclusively on the CITT results.

\section{Performance of intradermal tests (SITT and CITT)}

Using the CITT 32 out of 50 cows were positive. Twenty-one animals that were previously reactive to the SITT were all confirmed as positive using the CITT. All 27 cows that were confirmed by PCR or bacterial culture were also identified by CITT.

\section{Performance of the IFN assay}

On day 0, 34 cows were positive by IFN. A total of 31 out of 34 were also CITT positive, while the remaining three IFN-pos/CITT-neg cows were positive by milk culture and therefore confirmed as infected. Additionally, M. bovis was cultured from one CITT-pos/IFN-neg cow and two CITTneg/IFN-neg cows. On day 7p.i, 28 cows were still IFN-pos; from these, 13 were infected, with nine positive by culture or PCR and the others positive by CITT. One of these cows had not reacted on the first IFN testing performed at day 0. On day 21p.i., 28 out of 50 cows were still IFN positive. In brief, 21 cows were positive to IFN at the three different time points and thirteen of them were confirmed positive by culture and or PCR.

\section{Performance of ELISAs for MPB70 and MPB83}

ELISA-MPB70 was reactive for a total of 16 cows. From these, 11 were also CITT-pos. Ten cows were ELISA-MPB83 positive. From the remaining five cows that were CITT-neg/ ELISA MPB70/83-pos, M. bovis was recovered from two of them. On day $7 p . i$. , there were 13 out of 50 cows reactive by the ELISA-MPB70, while ELISA-MPB83 was reactive to 12 out of 50, these were also positive by the ELISA-MPB70. Seven of them reacted also to CITT. The same two CITT-neg/ 
Table 1. Number of positive cows according to ELISA, CITT and IFN at three different moments of testing

\begin{tabular}{lccc}
\hline \multicolumn{1}{c}{ Tests } & Day “0” & Day 7 p.i. $^{2}$ & Day 21 p.i. $^{2}$ \\
\hline IFN x CITT & 32 & 25 & 24 \\
IFN only & 3 & 3 & 4 \\
CITT only & 1 & 4 & 4 \\
ELISA x CITT & 11 & 7 & 7 \\
ELISA only & 5 & 6 & 4 \\
CITT only & 16 & 25 & 25 \\
ELISA x IFN & 11 & 6 & 6 \\
ELISA x IFN x CITT & 8 & 6 & 6
\end{tabular}

${ }^{1}$ Day 0 = Day of PPD inoculation; ${ }^{2}$ p.i. $=$ post-inoculation

Table 2. Sensitivity and specificity's values (\%) of ELISA and IFN assay taking CITT, culture and/or PCR as standards at three different moments

\begin{tabular}{lccccccc}
\hline \multirow{2}{*}{ Tests } & \multicolumn{3}{c}{ Sensitivity } & & \multicolumn{3}{c}{ Specificity } \\
\cline { 2 - 4 } \cline { 6 - 8 } & Day 0 & Day 7 p.i. & Day 21p.i. & & Day 0 & Day 7 p.i. & Day 21p.i. \\
\hline IFN & 91.4 & 74.3 & 71.4 & & 86.7 & 86.7 & 80 \\
ELISA & 34.4 & 53.8 & 21.8 & & 75 & 66.6 & 77.7
\end{tabular}

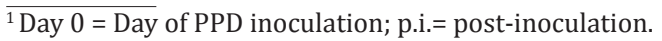

ELISA-pos cows at the day 0 were considered as infected (culture and/or PCR). On day 21p.i., there were 11 out of 50 cows reactive at both ELISAs. The two CITT-neg/ELISAs-pos cows identified previously as reactive, by culture and/ or PCR, were also considered infected. Two cows that were negative on ELISAs at day 0 and 7p.i. became reactive at this time. Four other cows that presented negative results at day 0 or day $7 p . i$. became reactive at day 21p.i (Table 1 ).

\section{Statistics}

IFN assay: Sensitivity and specificity of the IFN assay were calculated, using the standard tests described above. Concordance between IFN and the standard tests was calculated using the Kappa test. The sensitivity of the IFN test, when applied as a diagnostic tool (day 0 ) was $91.4 \%$, with a specificity of $86.7 \%$. When this assay was applied seven and 21 days p.i., sensitivities were 74.3 and $71.4 \%$, whereas specificities were 86.7 and $80 \%$ respectively. Although there was a slight change of these values, they presented no statistic relevance. The IFN is moderately comparable to CITT, on all three days of sampling $(k=0.50)$.

ELISAs: Results for the MPB70 and MPB83 ELISAs using the kappa statistic were in a substantial agreement for all the three-time points $(k=0.92)$. Therefore, for statistical purposes, the two ELISAs were analyzed and discussed as one. At day 0, kappa analysis showed a good degree of concordance $(k=0.7)$ between CITT and ELISAs, with a sensitivity of $34.4 \%$ and a specificity of $75 \%$. At day $7 p . i$, the sensitivity of the ELISA was $53.8 \%$ and the specificity $66.6 \%$, demonstrating a fair agreement $(k=0.25)$. At day 21p.i., the sensitivity of the ELISA was $21.8 \%$ and specificity was $77.7 \%$ There was a weak correlation between CITT and ELISA $(k=0.009)$ (Table 2).

\section{DISCUSSION}

This study was performed in a cattle herd that was undergoing a natural tuberculosis outbreak. In order to evalua- te the performance of different diagnostic tools for TB in cattle, IFN, ELISA, bacteriological culture and PCR were compared to CITT. As observed previously, IFN and CITT presented similar results, identifying almost overlapping populations of animals, in agreement with the literature (Lilenbaum 1999, Medeiros et al. 2010).

The IFN assay is widely used to detect early infection in animals or to confirm the results of the CITT (Vordemeier et al. 2004, Marassi et al. 2009b, Houlihan 2010), and is considered to have adequate sensitivity for diagnostic purposes. Wood \& Jones (2001) in a comprehensive review also reported that IFN could identify TB positive animals at an earlier time point compared to the CITT, and in some cases positively reacting animals were identified at 14 days post infection (Buddle et al. 1995). However, due to its relatively high cost, this assay has been recommended as an auxiliary test (Marassi et al. 2009b) to compliment the tuberculin test and mostly in cattle where there is a high probability of infection. Our results demonstrated that IFN was an effective diagnostic tool at the three time points chosen in our study and the test outcome was not altered by the injection of PPD at the time of the tuberculin test. Therefore this assay could be used either in diagnosis or as a confirmatory assay.

Tuberculosis in cattle can progress slowly, generally provoking cellular immunity within the host in the first instance. As the microbiological load increases, cellular response tends to decrease, while the humoral response increases and is more evident and detectable (Medeiros et al., 2010). Both types of skin test (in vivo) and the IFN assay (in vitro) measure the cellular response to infection. Therefore, depending on the particular stage of the disease, particularly during anergy, each of these tests may be negative since this response may no longer be detectable. In order to identify these animals, a number of studies focused on the recognition of $M$. bovis antigens that could be used to demonstrate a humoral response within the infected animals, thereby improving diagnosis of infection (Surujballi et al. 2002, Aagard et al. 2006). Indirect ELISAs using MPB70 and MPB83 have been used as alternative (or complementary) diagnostic tools in order to improve detection of cattle that do not react to tuberculins, the so called anergic reaction (De la Rua-Domenech et al. 2006). The reported sensitivity of these tests varies from $50 \%$ to $75 \%$, while specificity ranges between 90 and $95 \%$ when compared to CITT (Lilenbaum 1999, Silva 2001). In our study, the sensitivity of the ELISA on day 0 was lower than expected and could be explained by the introduction of new animals into the herd. There is the possibility that these new cows were infected upon introduction to the herd or may even have been in the early stages of infection during introduction. If this was the case then it would explain the poor sensitivity of the ELISA when antibody responses were absent or below the detectable level of the ELISA. Nevertheless, comparison between CITT and ELISA agree with other reports (Lilenbaum et al. 1999, De La Rua Domenech et al. 2006) that demonstrated that ELISA could identify animals that were anergic to CITT, indicate serological tests for detecting anergic cows. 
In contrast to other studies that identified a booster effect in the humoral response against MPB70 and MPB83 at two weeks post skin test (Thom et al. 2004), the ELISAs results in our study did not increase at days $7 p . i$. or 21p.i. The two antigens used as ELISA reagents in our study are capable of stimulating B-lymphocytes in the early phases of tuberculosis (McNair et al. 2001)

In addition, both of these antigens are components of bovine PPD and their presence could lead to a booster effect (Stevens et al. 1998). This effect could be most intense when an animal is really infected, or herd is located in an endemic area. In this situation, animals can have a great antibody titre with no lesions and did not react properly to the intradermal tests (Griffin 1990). In a study using BCG-vaccinated cattle and CITT testing, a booster effect on antibodies measured by ELISA following infection of bovine PPD was reported (Lyaschenko et al. 2004). It has also been reported that different strains of M.bovis could enhance different subclasses of IgG (Jolley et al. 2007), a factor that could contribute to the variation seen in ELISA results. Since the selection of an antigen for any assay is one of the most important steps in the development of that assay, the techniques by which that test is used can also be a determinant toward achieving higher levels of sensitivity and specificity (Jolley et al. 2007, Figueiredo et al. 2008). Nevertheless, the unexpected lack of a booster effect in our study remains unexplained.

Our results demonstrated that the immunoassays used in this study were not directly comparable, an observation not entirely surprising since each assay targets a different aspect of the immune response. Although the sensitivity of the ELISAs were lower than expected, statistical analysis suggested that each of the diagnostic tests evaluated could play a useful role in diagnosis, especially when there were animals in various stages of infection. Since tuberculosis is typically a chronic infection in a herd of this type and the immune response that follows infection is complex, our results suggest that individually, the tests currently available are not capable of detecting all infected cows with the herd. Although CITT is considered to be an excellent screening test and one that has contributed to the control of this disease worldwide (Monaghan et al. 1994), false-positive results can be recorded, erroneously identifying healthy animals as tuberculin reactors and unnecessary removal from the herd. False-negative results, particularly in the case of anergic cattle, allow infected animals to remain within the herd and to compromise the success of the disease control program. The IFN assay is relatively fast and easy test to perform and has the sensitivity to identify animals in the early stages of the disease. However, this assay will not detect animals in the later stages of infection or those which are anergic. The cost of this assay may be prohibitive especially when used in large scale disease control programmes. PCR methods and bacterial culture are very specific tests but with the exception of milk samples, they can only be performed post mortem, and may present variable results. Under these conditions, they are more useful as confirmatory tools rather than primary diagnostic tests for the epidemiologic control of outbreaks. In contrast, serological assays are relatively easy to perform and are inexpensive. However, it should be borne in mind that in their various forms ELISA's have a range of sensitivity and specificity indexes and require further improvements to improve efficiency.

\section{CONCLUSION}

This study demonstrated that the ranges of tests that are currently available are not sufficiently effective to be used alone and will not detect all infected cows during all stages of infection. Therefore, a multidisciplinary approach for diagnosis and control of tuberculosis would be more effective to identify all animals infected animals irrespective of the stage of the disease. A more effective strategy should include tests that target the detection of cellular and humoral immune responses, supported by bacteriological culture or PCR to confirm infection.

Conflict of interest.- All the authors affirm that there is no association that might pose a conflict of interest, such as, pharmaceutical stock ownership, consultancy, advisory board membership, relevant patents, or research funding, which could interfere with the results achieved in this study.

Acknowledgements.- To FAPERJ, CAPES and CNPq for financial support, to Dr. Jim McNair for disposing the antigens for this study, and to Prof. Flavia G. Silvestre and Prof. Joab Trajano Silva for their unquestionable assistance.

\section{REFERENCES}

Aagaard C., Govaerts M., Meikle V., Vallecillo A.J., Gutierrez-Pabello J.A., Suarez-Güemes F., McNair J., Cataldi A., Espitia C., Andersen P. \& Pollock J.M. 2006. Optimizing antigen cocktails for detection of Mycobacterium bovis in herds with different prevalence of bovine tuberculosis: ESAT6-CFP10 mixture shows optimal sensitivity and specificity. J. Clin. Microbiol. 44(12):4326-4335.

Almeida R.F.C., Madruga C.R., Soares C.O., Fernandes M.C., Carvalho N.M., Jorge K.S.G. \& Osorio A.L.A.R. 2006. Resposta imune específica de bovinos experimentalmente sensibilizados com inóculos inativados de Mycobacterium bovis e Mycobacterium avium. Pesq. Vet. Bras. 26(4): 195-200.

Amanfu W. 2006. The situation of tuberculosis and tuberculosis control in animals of economic interest. Tuberculosis 86:330-335.

Buddle B.M., Lisle G.W., Pfeffer A. \& Aldwell F.E. 1995. Immunological responses and protection against Mycobacterium bovis in calves vaccinated with a low dose of BCG. Vaccine 13(12):1123-1130.

De la Rua Domenech R., Goodchild A.T., Vordemeier H.M., Hewinson R.G. \& Christiansen K.H. 2006. Ante-mortem diagnosis in cattle: A review of the tuberculin tests, gamma-interferon assay and other ancillary diagnostic techniques. Res. Vet. Sci. 81:190-210.

El-Zaatar F.A., Nase S.A., Engstran L., Burc P.E., Hachem C.Y., Whipple D.L. \& Graham D.Y. 1995. Nucleotide sequence analysis and seroreactivities of the $65 \mathrm{~K}$ heat shock protein from Mycobacterium paratuberculosis. Clin. Diagn. Lab. Immunol. 2(6):657-664.

Figueiredo E., Silvestre F.G., Campos W.N., Furlanetto L., Medeiros L., Lilenbaum W., Fonseca L.S., Silva J.T. \& Paschoalin V. 2008. Identification of Mycobacterium bovis Isolates by a multiplex PCR. Braz. J. Microbiol. 39:1-4.

Griffin J.F.T. 1991. Tuberculosis in domesticated red deer: Comparison of purified protein derivative and the specific MPB70 for in vitro diagnosis. Res.Vet.Sci. 50:279-285.

Houlihan M. 2010. Isolation of Mycobacterium kansassi from calf reactors in a TB-restricted dairy herd. Vet. Rec. 166:272-273. 
Jolley M.E., Nasir M.S., Surujballi O.P., Romanowska A., Renteria T.B., De la Mora A., Lim A., Bolin S.R., Michel A.L., Kostovic M. \& Corrigan E.C. 2007. Fluorescence polarization assay for the detection of antibodies to Mycobacterium bovis in bovine sera. Vet. Microbiol. 16:113-121.

Lightbody K.A., McNair J., Neill S.D. \& Pollock J.M. 2000. IgG isotype antibody responses to epitopes of the Mycobacterium bovis protein MPB70 in immunized and in tuberculin skin test-reactor cattle. Vet. Microbiol. 75(2):177-188.

Lilenbaum W. 1999. 0 uso do ELISA para o diagnóstico da tuberculose bovina no Brasil: uma possibilidade interessante? Revta Bras. Med. Vet. 21(1):28-31.

Lilenbaum W., Schettini J.C., Souza G.N., Ribeiro E.R., Moreira E.C. \& Fonseca L.S. 1999. Comparison between a gamma-IFN assay and intradermal tuberculin test for the diagnosis of bovine tuberculosis in field trials in Brazil. J. Vet. Med. B 46:353-358.

Lilenbaum W., Marassi C.D. \& Medeiros L. 2011. Use of MPB70 ELISA as a complementary test for bovine TB in the field in Brazil. Vet. Rec.168:167168.

Lin M.Y., Geluk A., Smith S.G., Stewart A.L., Friggen A.H., Franken K.L.M.C., Verduyn M.J.C., Meijgaarden K.E., Voskuil M.I., Dockrell H.M., Huygen K., Ottenhoff T.H.M. \& Klein M.R. 2007. Lack of immune responses to Mycobacterium tuberculosis dos Regulon Proteins following Mycobacterium bovis BCG vaccination. Infect. Immun.75(7):3523-3530.

Lyaschenko K., Whelan A.O., Greenwald R., Pollock J.M., Andersen P., Hewinson R.G. \& Vordemeier H.M. 2004. Association of tuberculin-boosted antibody responses with pathology and cell-mediated immunity in cattle vaccinated with Mycobacterium bovis BCG and infected with $M$. bovis. Infect. Immun. 72(5):2462-2467.

Marassi C.D., McNair J., Pollock J., Ristow P., Fonseca L., Oelemann W.M.R. \& Lilenbaum W. 2009(a). The use of MPB70 and MPB83 to distinguish between bovine tuberculosis and paratuberculosis. CIMID 33:485-489.

Marassi C.D., Medeiros L. \& Lilenbaum W. 2009(b). The use of Gamma-Interferon assay to confirm a diagnosis of Bovine Tuberculosis in Brazil. Acta Tropica 113(2):199-201.

McNair J., Corbett D.M., Girvin R.M., Mackie D.P. \& Pollock J.M. 2001. Characterization of the early antibody response in bovine tuberculosis: MPB83 is an early target with diagnostic potential. Scand. J. Immunol. 53:365-371.

Medeiros L., Marassi C.D., Figueiredo E. \& Lilenbaum W. 2010. Potential application of new diagnostic methods for controlling bovine tuberculosis. Braz. J. Microbiol. (In press). DOI: 10.1590/S151783822010005000002.

Monaghan M.L., Doherty M.L., Collins J.D., Kazda J.F. \& Quinn P.J. 1994. The tuberculin test. Vet. Microbiol. 40(1/2):111-124.

Neill S.D., Pollock J.M., Bryson D.B. \& Hanna J. 1994. Pathogenesis of Mycobacterium infection in cattle. Vet. Microbiol. 40:41-52.
Olsen I., Tryland M., Wiker H.G. \& Reitan L.J. 2001. AhpC AhpD and a secreted $14 \mathrm{kDa}$ antigen from Map distinguish between paratuberculosis and bovine tuberculosis in an ELISA assay. Clin. Diagn. Lab. Immunol. 8:797-803.

Pollock J.M., Welsh M.D. \& McNair J. 2005. Immune response in bovine tuberculosis: towards new strategies for the diagnosis and control of disease. Vet. Immunol. Immunopathol. 108:37-43.

Rodgers J.D., Connery N.L., McNair J., Welsh M.D., Skuce R.A., Bryson D.G., McMurray D.N. \& Pollock J.M. 2007. Experimental exposure of cattle to a precise aerosolized challenge of Mycobacterium bovis: A novel model to study bovine tuberculosis. Tuberculosis 87:405-414.

Ryan T.J., Buddle B.M. \& De Lisle G.W. 2000. An evaluation of the gamma interferon test for detecting bovine tuberculosis in cattle 8 to 28 days after tuberculin skin testing. Res. Vet. Sci. 69:57-61.

Silva E. 2001. Evaluation of an enzyme-linked immunosorbent assay in in the diagnosis of bovine tuberculosis. Vet. Microbiol. 78:111-117.

Stevens J.B., Thoen C.O., Rohonczy E.B., Tessaro S., Kelly H.A. \& Duncan J.R. 1998. The immunological response of llamas (Lama glama) following experimental infection with Mycobacterium bovis. Can. J. Vet. Res. 62:102-109.

Surujballi O.P., Romanowska A., Sudgen E.A., Turcotte C. \& Jolley M.E. 2002. A fluorescence polarization assay for the detection of antibodies to Mycobacterium bovis in cattle sera. Vet. Microbiol. 87:149-157.

Thom M., Morgan J.M., Hope J.C., Ramos B.V., Martin M. \& Howard C.J. 2004. The effect of repeated tuberculin skin testing of cattle on immune responses and disease following experimental infection with Mycobacterium bovis. Vet. Immunol. Immunopathol. 102:399-412.

Vordermeier H.M., Rhodes S.G., Dean G., Goonetilleke N., Huygen K., Hill A.V.S., Hewinson R.G. \& Gilbert S.C. 2004. Cellular immune responses induced in cattle by heterologous prime-boost vaccination using recombinant viruses and Bacille Calmette-Guérin. Immunology 112(3):461470.

Water W.R., Palmer M.V., Thacker T.C., Bannantine J.P., Vordemeier H.M., Hewinson R.G., Greenwald R., Esfandiari J., McNair J., Pollock J.M. Andersen P. \& Lyashchenko K.P. 2006. Early antibody responses to experimental Mycobacterium bovis infection of cattle. Clin. Vac. Immunol. 13(6):648-654.

WHO-WorldHealth Organization<http://www.who.int/zoonoses/neglect zoonotic disease/en/> Accessed on June 2, 2009.

Wiker H.G. 2009. MPB70 and MPB83 - major antigens of Mycobacterium bovis. Scand. J. Immunol. 69:492-499.

Wood P.R. \& Jones S.L. 2001. BOVIGAM ${ }^{\mathrm{TM}}$ : An in vitro cellular diagnostic test for bovine tuberculosis. Tuberculosis 81(1/2):147-155.

Wood P.R., Rothel J.S., McWathers P.G.D. \& Jones S.L. 1990. Production and characterization of monoclonal antibodies specific for bovine gamma-interferon. Vet. Immun. Immunopathol. 25:37-46. 